\title{
Hydration Heat of Nonshrinkage Concrete in Large-Diameter CFST Arch Ribs Cured at Low Temperatures
}

\author{
Tuo Shi $\left(\mathbb{D},{ }^{1}\right.$ Nianchun Deng $\left(\mathbb{D},{ }^{1}\right.$ Dong Pan, ${ }^{2}$ and Shi Wang ${ }^{3}$ \\ ${ }^{1}$ College of Civil Engineering and Architecture, Guangxi University, Nanning, Guangxi, China \\ ${ }^{2}$ Guangxi Traffic Engineering Testing Co., Ltd., Nanning, Guangxi, China \\ ${ }^{3}$ Tibet Railway Construction Co. Ltd., Nanning, Guangxi, China \\ Correspondence should be addressed to Nianchun Deng; dengnch@gxu.edu.cn
}

Received 19 May 2020; Revised 7 November 2020; Accepted 13 November 2020; Published 23 November 2020

Academic Editor: Leonidas Alexandros Kouris

Copyright (c) 2020 Tuo Shi et al. This is an open access article distributed under the Creative Commons Attribution License, which permits unrestricted use, distribution, and reproduction in any medium, provided the original work is properly cited.

\begin{abstract}
To study the construction of concrete-filled steel tubular (CFST) arch bridges in Tibet, China, the hydration-temperature field of nonshrinkage concrete in large-diameter CFST arch ribs was evaluated in a temperature-testing box to simulate a low-temperature environment. A finite element simulation was then conducted to replicate the experimental results. Finally, an improved formula with the parameters related to the diameter, the position, and the retarding time of concrete for predicting the hydration heat generated by non-shrinkage concrete in large-diameter CFST arch ribs cured at low temperatures was proposed. The formula results were shown to be consistent with the experimental results for low-temperature conditions and large diameters. This research method can be extended to predict the hydration heat at all locations in different-diameter CFSTs with different concrete mixes cured at various temperatures.
\end{abstract}

\section{Introduction}

Concrete-filled steel tubular (CFST) arch bridges can, under suitable conditions, be constructed for half the cost of a suspension bridge with the same span [1]. As a result, many CFST arch bridges have been built to carry highway and railway traffic in the past 20 years in China. At present, more than 400 CFST arch bridges have been built in country, and the longest spans are 530 and $575 \mathrm{~m} \mathrm{[2].} \mathrm{The} \mathrm{pouring} \mathrm{of}$ concrete into steel tubes is key to constructing CFST arch bridges, and various high-performance concretes (e.g., nonshrinkage and self-compacting) have been applied [3].

Hydration heat occurs during the curing of concrete and has been studied experimentally by many scholars. Zhou et al. [4] conducted experimental research and numerical simulations on the early hydration heat and stress in a concrete wall, showing that insulation measures were necessary during cold weather. A microsimulation of hydration heat under creep was carried out by Briffaut et al. [5], who determined that the rate of increase in the elastic stiffness and the tensile strength of ordinary concrete were reduced under higher hydration heat. Byard et al. [6] studied the hydration performance of concrete that included prewetted lightweight aggregate and found an increased degree of hydration. Zhou et al. [7] conducted hydration heat tests and finite element simulation analyses on a new impermeable concrete, determining that high or low ambient temperatures were not conducive to a reduction in the temperature difference caused by concrete hydration. Through experiments, Sedaghat et al. [8] established an empirical formula for the hydration heat of Portland cement cured at $23^{\circ} \mathrm{C}$. Li et al. [9] studied the influence of nanoalumina and graphene oxide on the early hydration of cement. Their experimental research showed that both materials could increase the hydration heat of cement and accelerate the hydration process. Hu et al. [10] studied the effect of different functional agglomerations of carboxylic acid superplasticizer on the hydration heat of cement paste, showing that different functional units had different effects on the retarding time and peak hydration of the cement paste. Tan et al. [11] studied the effect of fly ash on the hydration of magnesium sulfate slurry using electrochemical impedance spectroscopy and confirmed the validity of this new research method through testing. Chorzepa et al. [12] established a multifactor hydration model simulation and 
carried out test verification, showing that the effect of the hydration model was significant. Chen and Xu [13] investigated the hydration-temperature field of three CFST members, observing that, after filling the steel tube with concrete, the cross section temperature of each member was higher than the ambient temperature. These results demonstrated that the temperature field was characterized by high inside and low outside temperatures. The maximum temperature difference between the inside and outside reached $8.5^{\circ} \mathrm{C}$. Feng [14] conducted hydration-temperature field tests on circular and square CFST members showing that their cross section temperatures first increased and then decreased before finally approaching the atmospheric temperature. The temperature difference between the atmosphere and the square CFST members was greater than that between the atmosphere and the circular CFST members. Lin et al. $[15,16]$ tested a CFST arch having an outer diameter of $325 \mathrm{~mm}$ and a span of $10 \mathrm{~m}$. The hydration temperature of the concrete in the test arch rib was similar to that of mass concrete; the temperature first increased and then decreased, and a temperature gradient was observed in the section. Xuan [17] observed that the temperature gradients and stresses observed in a CFST arch bridge having a $60 \mathrm{~m}$ span were likely caused by a higher hydration heat occurring when the arch-rib concrete was poured at low temperatures. Sun et al. [18] suggested that the thickness of the steel tube used in a CFST arch had less influence on the hydration-temperature field than did the diameter of the tube. Gao [19] conducted experiments and finite element analyses on CFST members and concluded that the outer surfaces of the CFST section were more affected by the ambient temperature than was the core over the first 7 days of hydration.

Experts and scholars have thus explored the temperature field of hydration heat in CFST arch bridges, but the sizes and quantities of the test specimens in previous studies were too small to be applied to full-span bridges, the test conditions were not sufficiently controlled, and there was little research at low temperatures. Therefore, further research is urgently needed. With more CFST arch bridges currently being built for the Sichuan-Tibet Railway, it is important to study the hydration heat in large-diameter CFST arch ribs cured at low temperatures. This study addresses these gaps. The diameters of the CFST members tested in this study were sufficiently large to explore the temperature field of the hydration heat, and a temperature test box was employed to ensure specimen curing at consistently low temperatures. The results of this research were then used to reveal the law of hydration-heat temperature change of nonshrinkage concrete in large-diameter CFSTs cured at low temperatures and to predict the temperatures of different-diameter CFSTs at an early age at different locations using an empirical equation. This advancement could provide a helpful reference for the construction of CFST arch bridges in winter in Tibet.

\section{Experimental Means and Methods}

The experiments conducted in this study were designed to evaluate the development of the hydration-heat temperature field in $1.4 \mathrm{~m}$ and $1.6 \mathrm{~m}$ diameter CFST members in a temperature test box. The specific dimensions of the members are shown in Figures 1 and 2 shows photos of the members. The mixing proportion of C55 nonshrinkage concrete used in the CFST members is shown in Table 1. The C55 concrete mix applied in this study was selected based on the results of a previous study showing good volume stability and mechanical properties of this mix in CFSTs cured at low temperature [20].

Because the influence of the CFST arch rib angle on the temperature field of the hydration heat could be ignored, the test pieces were oriented vertically in the temperature box to facilitate the placement of concrete. Four locating rings were welded within each steel tube, and high-strength insulated wire ropes were fixed to them across the test section to provide a lattice for attaching the temperature sensors (i.e., thermal resistors), as shown in Figure 3. Note that a No.0 measuring point was also placed in the temperature test box to measure the ambient temperature. A wireless data acquisition system was used to acquire the temperature and stress data. The range of temperature sensors was from $-30^{\circ} \mathrm{C}$ to $+120^{\circ} \mathrm{C}$, whose accuracy was $0.2^{\circ} \mathrm{C}$.

After the sensors were installed, the CFST members were placed in the temperature test box (Figure 4), and the data acquisition system was connected. The temperature in the temperature test box was set to $0^{\circ} \mathrm{C}$. The nonshrinkage concrete was then poured into the $1.4-\mathrm{m}$ and $1.6-\mathrm{m}$ diameter CFST members (Figure 5) at initial casting temperatures of 28 and $30^{\circ} \mathrm{C}$, respectively. After casting was complete, the ends of the members were sealed with steel plates and insulation material to ensure that heat radiated from only the walls of the tubes. Finally, the temperature test box was closed. Data were then collected every $10 \mathrm{~min}$ starting from the beginning of pouring to obtain the temperature variation of the concrete during the process of hydration heat release. The testing was terminated after 7 days.

\section{Results and Analysis}

The hydration heats in the 1.4- and 1.6-m diameter CFST members exhibited consistent changes over time. The hydration temperatures of the concrete in the CFST members were centrosymmetric. Thus, only one quarter of the measured points (Nos. 1, 2, 3, and 4) and the ambient temperature (No. 0) were selected for data plotting and analysis. The temperatures of the concrete in the members rapidly reached their maximum after $20 \mathrm{~h}$ in the low-temperature test box (Figure 5) and then decreased gradually until equalizing near the ambient temperature. As can be observed in Figure 5, the concrete near the edge of the steel tube was more affected by the low ambient temperature.

The initial casting temperature of the $1.4-\mathrm{m}$ diameter CFST member was $28^{\circ} \mathrm{C}$, and its maximum temperature during hydration was $62.1^{\circ} \mathrm{C}$, indicating a temperature increase of $34.1^{\circ} \mathrm{C}$ caused by hydration heat. The initial casting temperature of the $1.6-\mathrm{m}$ diameter CFST member was $30^{\circ} \mathrm{C}$, and its maximum temperature during hydration was $72.8^{\circ} \mathrm{C}$, indicating a temperature increase of $42.8^{\circ} \mathrm{C}$ caused by hydration heat. Therefore, the larger-diameter CFST corresponded to a higher maximum hydration heat. The 


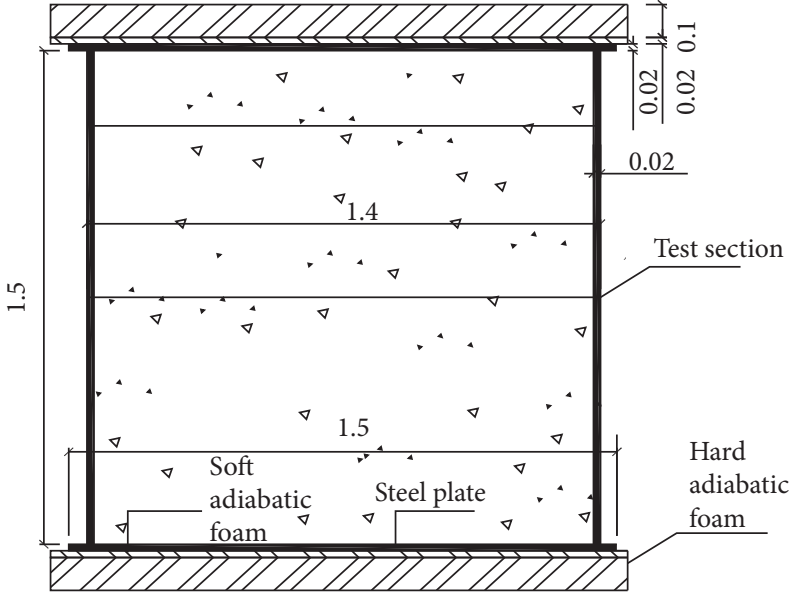

(a)

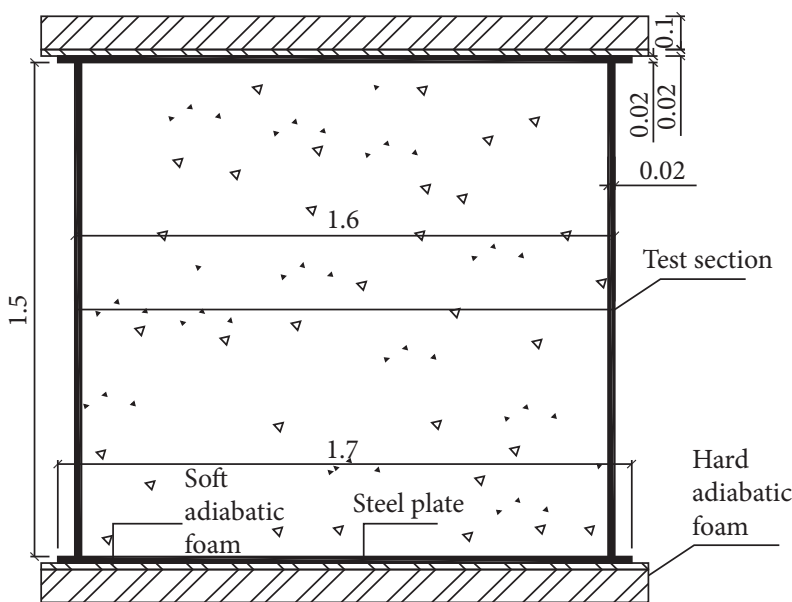

(b)

Figure 1: Dimensions of the CFST members evaluated in this study (m). (a) $1.4 \mathrm{~m}$ diameter. (b) $1.6 \mathrm{~m}$ diameter.

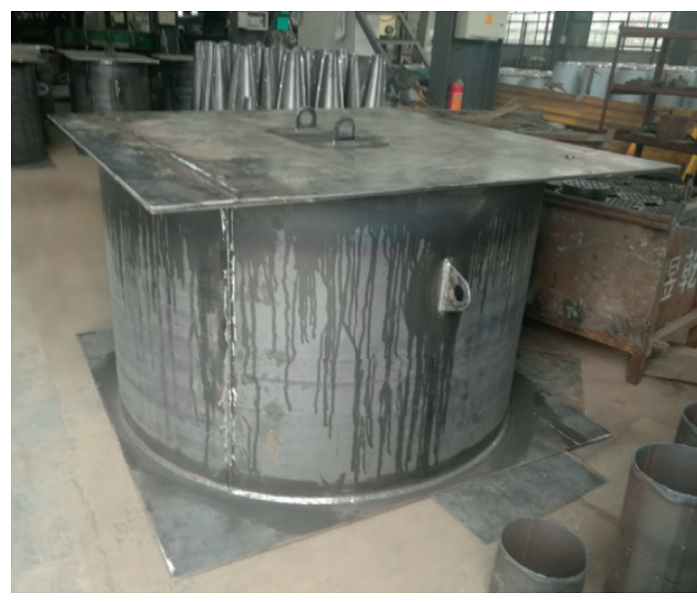

(a)

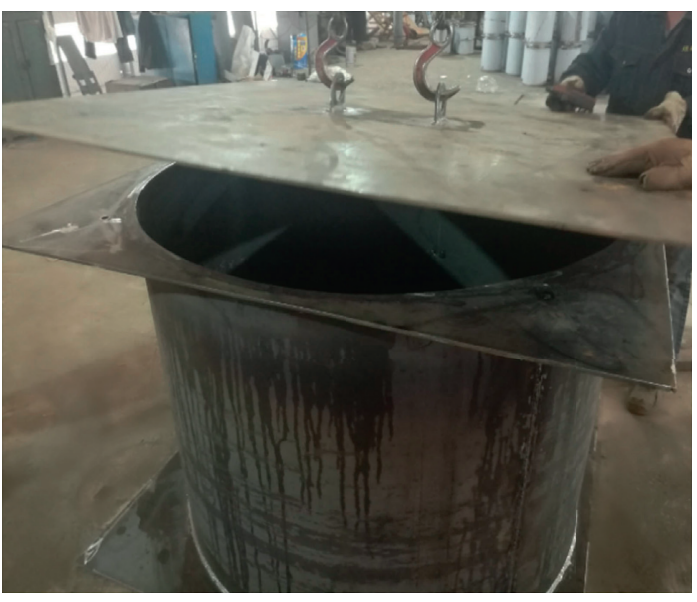

(b)

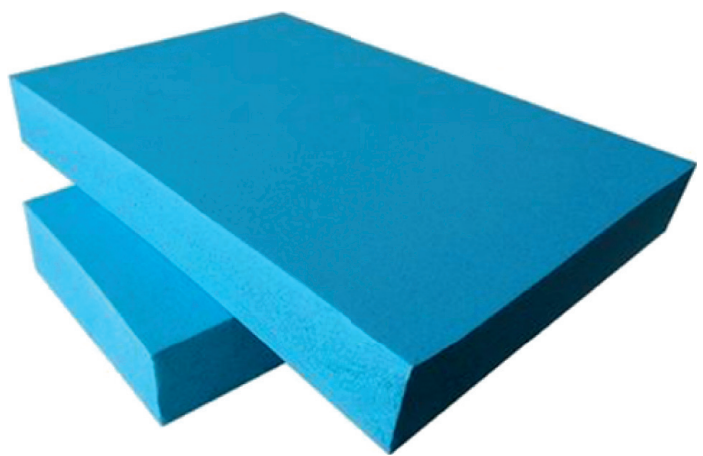

(c)

Figure 2: Photos of the CFST members evaluated in this study. (a) $1.4 \mathrm{~m}$ diameter. (b) $1.6 \mathrm{~m}$ diameter. (c) Hard adiabatic foam.

TABLE 1: Mixing proportion of C55 nonshrinkage concrete $\left(\mathrm{kg} / \mathrm{m}^{3}\right)$.

\begin{tabular}{lccccccc}
\hline Cement & Fly ash & Water-reducing agent & Expansive agent & Sand & Gravel & Water & Total \\
\hline 400 & 45 & 12.9 & 50 & 711 & 1.052 & 157 & 2.427 .9 \\
\hline
\end{tabular}




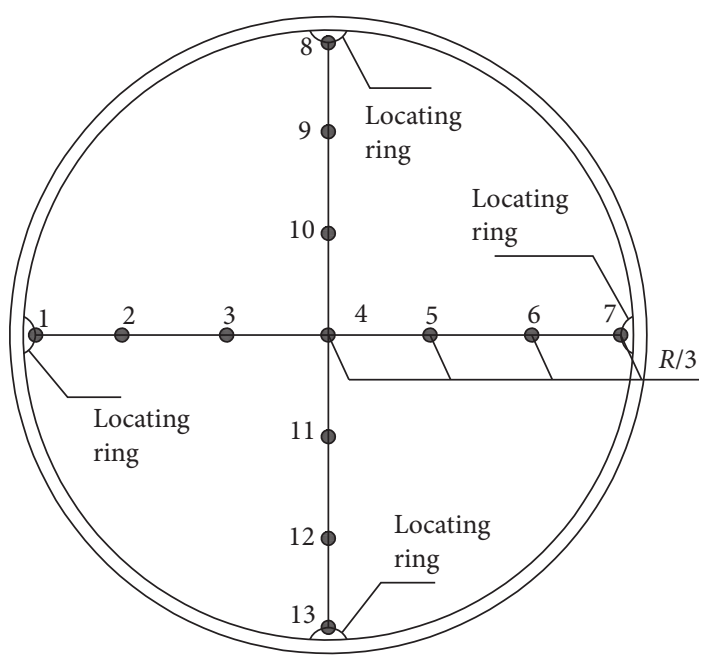

Figure 3: Layout of the measuring points.

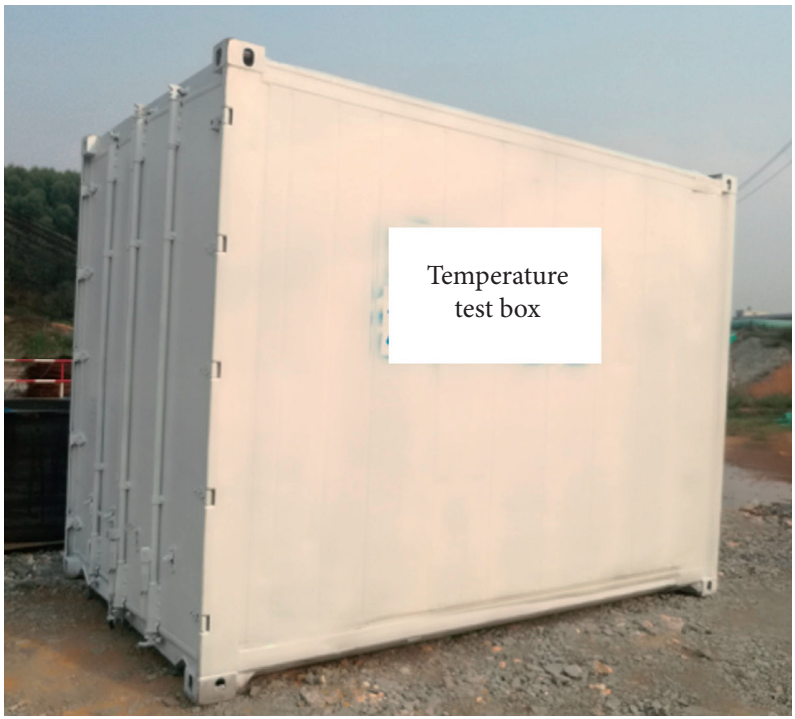

FIgURE 4: Temperature test box.

maximum difference in hydration heat measured within the 1.4- and 1.6- $\mathrm{m}$ diameter CFST members was 34.9 and $37.2^{\circ} \mathrm{C}$, respectively. Thus, a larger-diameter CFST will exhibit a greater difference in temperature, owing to hydration heat. The hydration-heat characteristics of the CFST specimens were similar to those of mass concrete, suggesting that there was a greater temperature difference caused by the hydration heat of the CFST cured at low curing temperatures. Owing to the low curing temperature and the large difference in temperature caused by hydration heat, the cooling rate of the concrete was also large.

A finite element analysis was conducted using ANSYS v.17.0 to further investigate the distribution of the hydration temperature of the nonshrinkage concrete in large-diameter CFST arch ribs. The PLANE77 element was selected to represent the concrete. The material parameters used in the finite element model are listed in Table 2. The model was divided into 4.161 nodes and 1.360 elements. The hydration-heat model was based on the composite exponential formula, and its parameters were selected from the literature [21]. The formula is given as follows:

$$
Q(t)=Q_{0}\left[1-\exp \left(m t^{n}\right)\right],
$$

where $Q(t)$ is the cumulative hydration heat at time $t$ at age $t$ (d), $Q_{0}$ is the final hydration heat, and $m$ and $n$ are coefficients of the rate of hydration heat.

The axial length of the specimen was $1.5 \mathrm{~m}$, and the diameters were $1.4 \mathrm{~m}$ and $1.6 \mathrm{~m}$, respectively. In the test, two layers of heat preservation material were placed to cover both ends of the specimen to prevent heat escape. Therefore, the influence of the environment on the temperature field in the axial direction of the specimen could be ignored. Furthermore, because the temperature field of the CFST members was assumed to be uniform, the model was simplified as a $2 \mathrm{D}$ model. The boundary temperature of the $2 \mathrm{D}$ model was set to $0^{\circ} \mathrm{C}$, and the heat-transfer coefficient 

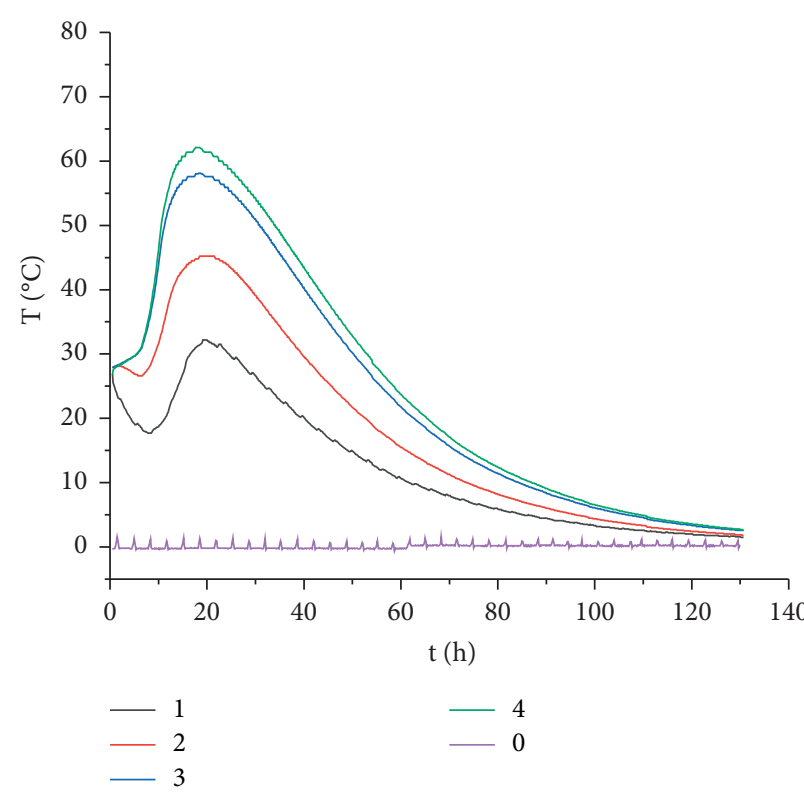

$-4$

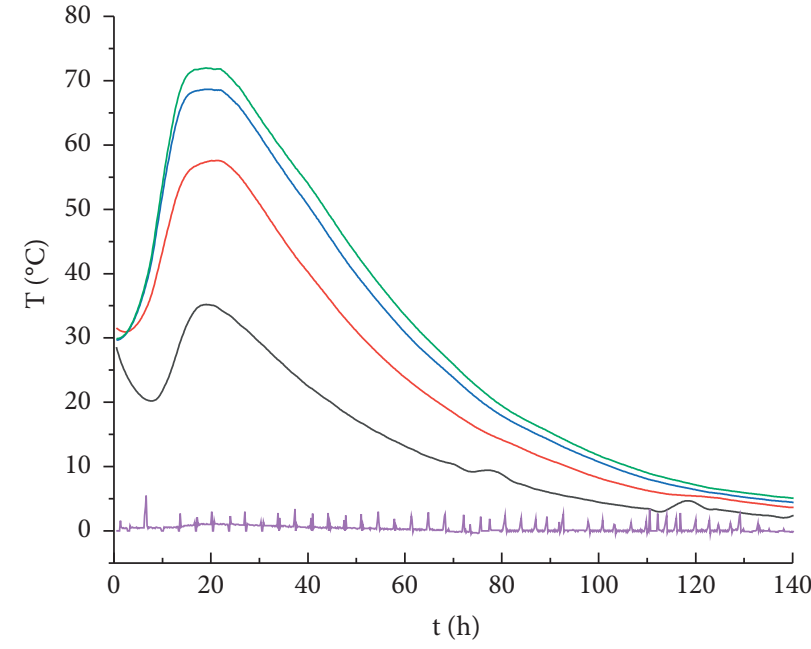

$\begin{array}{ll}- & 1 \\ - & 2\end{array}$

(a)

(b)

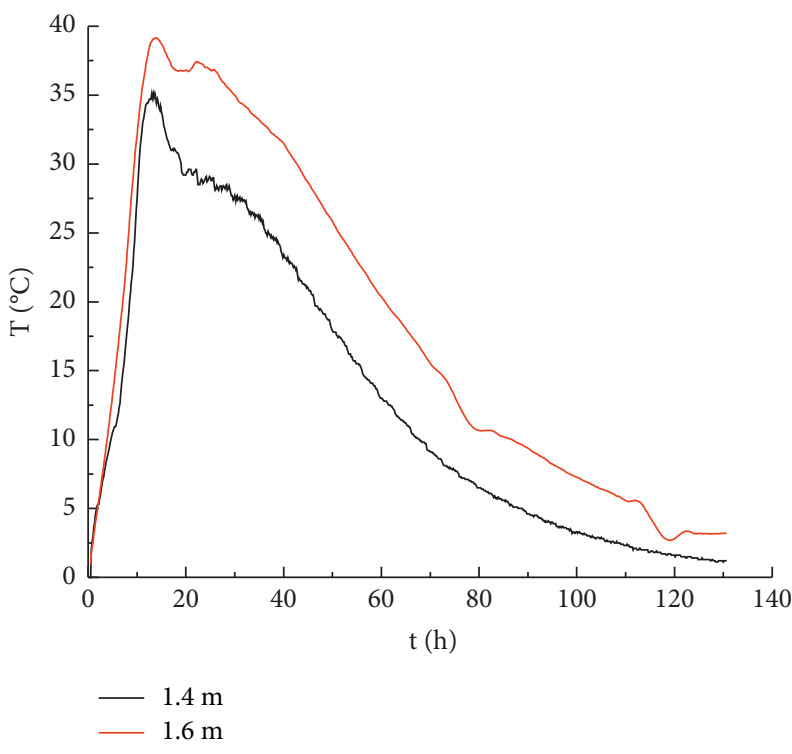

(c)

FIGURE 5: Change in hydration temperature in the CFST members over time when curing at $0^{\circ} \mathrm{C}$. (a) $1.4-\mathrm{m}$ diameter. (b) $1.6-\mathrm{m}$ diameter. (c) Maximum temperature difference.

TABLE 2: Thermal parameters of the materials used in the finite element model.

\begin{tabular}{lccc}
\hline Material & Density $\left(\mathrm{kg} / \mathrm{m}^{3}\right)$ & Specific-heat capacity $\left(\mathrm{kJ} / \mathrm{m}^{2}{ }^{\circ} \mathrm{C}\right)$ & Thermal conductivity $\left(\mathrm{kJ} / \mathrm{m}^{2} \cdot \mathrm{h}^{\circ} \mathrm{C}\right)$ \\
\hline Concrete & 2.450 & 0.98 & 10.09 \\
Steel & 7.850 & 0.45 & 199.124 \\
\hline
\end{tabular}

was $4.99 \mathrm{~W} / \mathrm{m}^{2}{ }^{\circ} \mathrm{C}$. The model mesh and selected measurement points are shown in Figure 6.

As indicated by the comparisons in Figure 7, the finite element analysis results agreed well with the experimental results: the heating and cooling sections of the hydrationheat curves were generally consistent, except during the initial concrete retarding phase. This result demonstrates that the finite element model established in the study was accurate, but that the composite exponential formula used to model the hydration heat could be improved for the early phase.

At the retarding stage, too low ambient temperature would affect the hydration rate and prolong the retarding time of concrete, so the retarding time of edge concrete was 


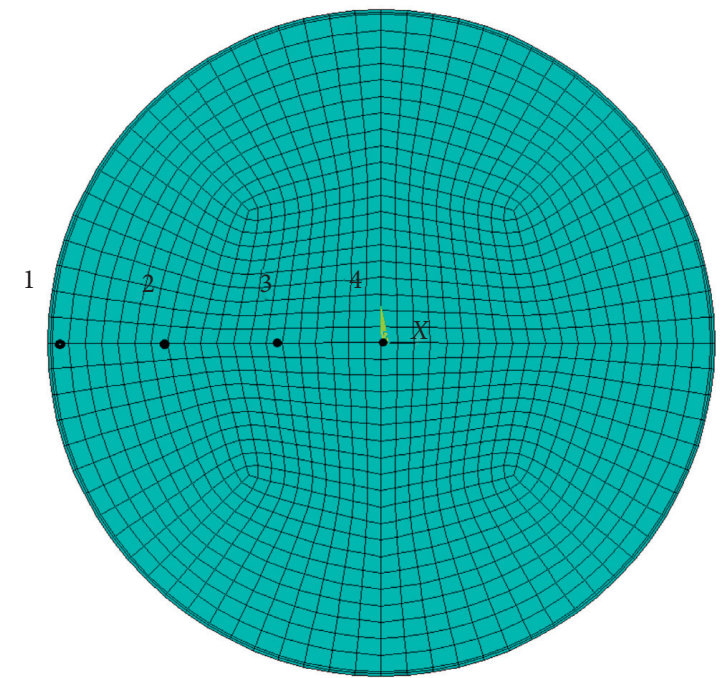

FIGURE 6: Finite element model and measuring-point locations.
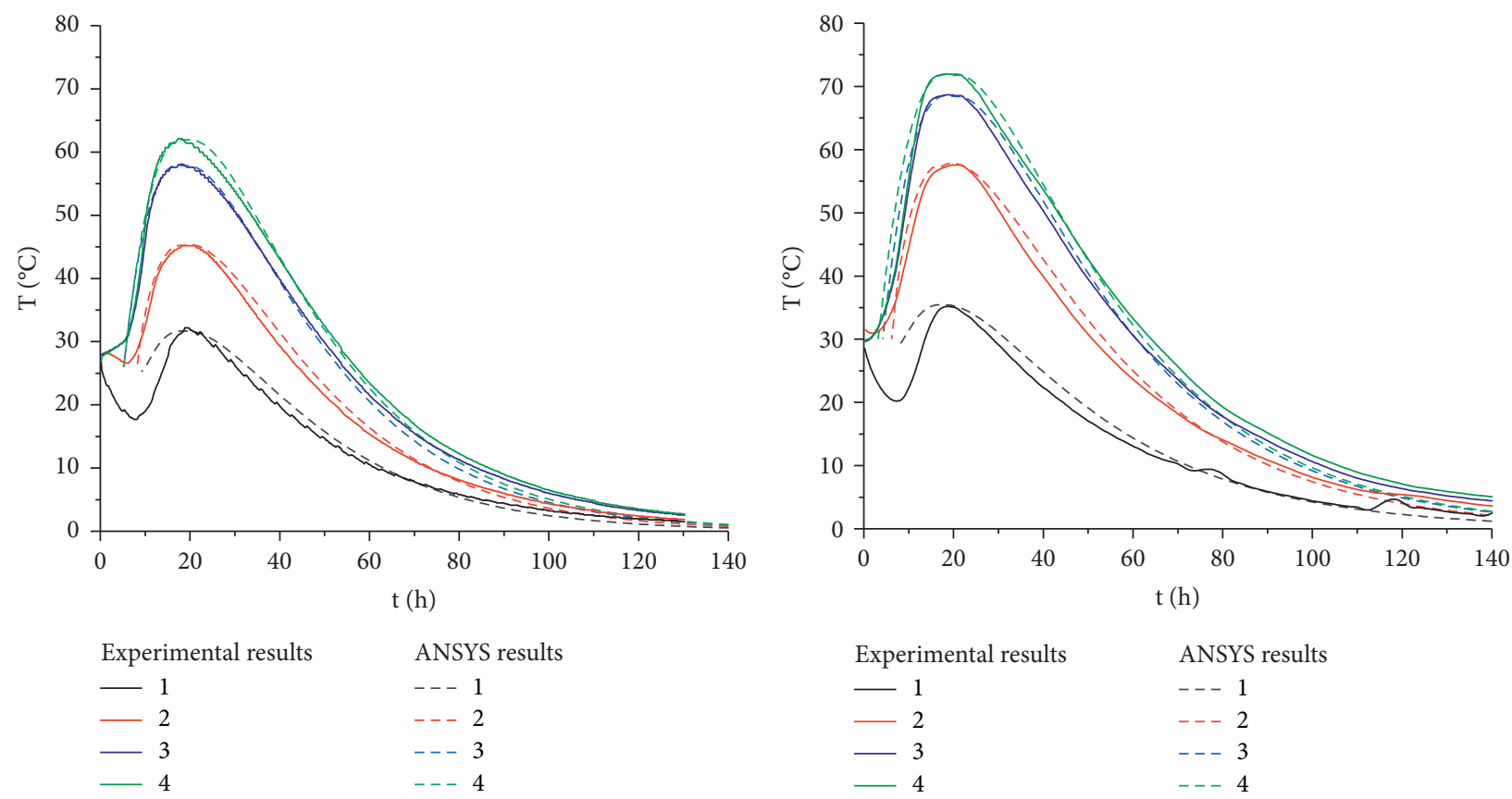

(a)

(b)

Figure 7: Comparison of experimental and finite element simulation results for (a) $1.4 \mathrm{~m}$ and (b) 1.6-m diameter members.

longer than that of core concrete. At the retarding stage of edge concrete, the temperature of concrete would decrease due to the influence of low ambient temperature. The finite element simulation could not simulate the retarding stage, so there were differences at the retarding stage.

\section{Discussion}

4.1. Improved Hydration Heat Formula. An improved formula was developed in this study based on the experimental and finite element simulation results. The formula was built upon the work of Lee et al. [22] and Koo et al. [23], who previously improved the formula for predicting hydration temperature. The applicable condition for their formula is a constant temperature or the quasi-adiabatic condition, given as follows:

$$
\Delta T(t)=\Delta T_{\max }\left[1-\exp \left(\mathrm{at}^{b}\right)\right],
$$

where $\Delta T(t)$ is the difference between the temperature of the concrete at age $t(\mathrm{~d})$ and its initial casting temperature, $\Delta T_{\max }$ is the maximum increase in temperature, and $a$ and $b$ are coefficients of the rate of temperature change.

As demonstrated by the early discrepancy in Figure 8, the initial retarding time of the nonshrinkage concrete 
was not considered in this formula. Furthermore, formula (4) was only able to calculate the maximum temperature difference at the center of the section. Notably, the law describing the hydration temperature of concrete in a CFST is related to the CFST diameter, and there are some regularities in the temperature-field distribution of the concrete hydration heat at any location within. Therefore, an improved formula was developed as follows:

$$
\Delta T(t)=\alpha_{D} \beta_{r} \Delta T_{\max }\left\{1-\exp \left[a\left(t-t_{0}\right)^{b}\right]\right\},
$$

where $\alpha_{D}$ is the diameter coefficient, defined as the ratio of the center temperature of the current-diameter CFST to the center temperature of a $1.5-\mathrm{m}$ diameter CFST, $\beta_{r}$ is the location coefficient, defined as the ratio of the temperature at the current location to that at the core, and $t_{0}$ is the retarding time of the concrete.

The heating and cooling phases at the core of a $1.5-\mathrm{m}$ diameter CFST were simulated to serve as benchmark data for formula (3). The maximum increase in temperature during the heating phase $\left(\Delta T_{\max 1}\right)$ was defined as the difference between the maximum temperature $\left(T_{\max }\right)$ and the initial casting temperature $\left(T_{1}\right)$. Thus, $\Delta T_{\max 1}=T_{\max }-T_{1}$. The maximum decrease in temperature in the cooling phase $\left(\Delta T_{\max 2}\right)$ was defined as the difference between the maximum temperature $\left(T_{\max }\right)$ and the ambient temperature $\left(T_{0}\right)$. Thus, $\Delta T_{\max 2}=T_{\max }-T_{0}$. The ambient temperature $\left(T_{0}\right)$ was $0^{\circ} \mathrm{C}$, the initial casting temperature of the concrete $T_{0}$ was $30^{\circ} \mathrm{C}$, and the maximum temperature $\left(T_{\max }\right)$ was $69^{\circ} \mathrm{C}$. Therefore, the maximum temperature increase during the heating phase was $\Delta T_{\max 1}=T_{\max }-T_{1}=39.4^{\circ} \mathrm{C}$. This value was fit according to formula (3) to obtain the coefficients, $a_{1}=-0.10$ and $b_{1}=1.35$. The maximum temperature decrease in the cooling phase was $\Delta T_{\max 2}=69.5^{\circ} \mathrm{C}$. This value was fit according to formula (3) to obtain the coefficients, $a_{2}=-7,875.4$ and $b_{2}=-2.35$. The calculated value obtained using the fitted formula (3) and the simulated values obtained from the finite element analysis were then compared and found to be similar, as shown in Figure 8.

4.2. Determination of Parameter $\alpha_{D}$. The parameter, $\alpha_{D}$ (the ratio of the current-diameter CFST center temperature to the $1.5-\mathrm{m}$ diameter CFST center temperature), in formula (3) was determined by the following method. First, CFST members having different diameters of 1.0, 1.2, 1.4, 1.6, 1.8, and $2.0 \mathrm{~m}$ were simulated using finite element software to obtain the center temperature curves of the shrinkage-free concrete, shown in Figure 9. Then, the different diameters were listed as abscissa coordinates, and the corresponding values of $\alpha_{D}$ were taken as ordinate coordinates. The resulting points for the seven evaluated diameters are plotted in Figure 10, as is the fitted curve plotted using the Origin software. The following fitting formula was obtained by taking the maximum increase in temperature using the $1.5-\mathrm{m}$ diameter CFST member as the benchmark, setting the diameter as the independent variable and $\alpha_{D}$ as the dependent variable:

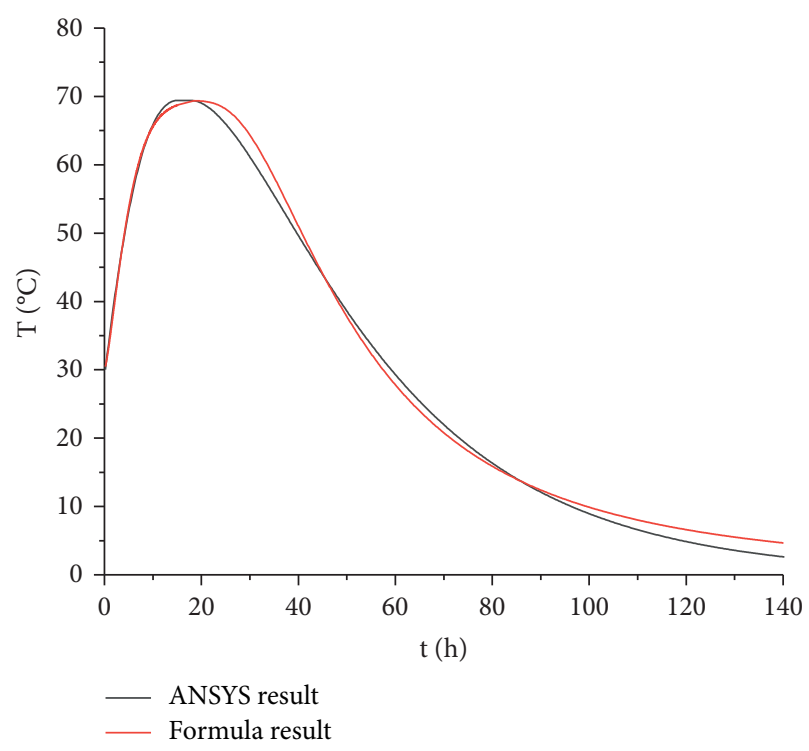

Figure 8: Comparisons of the core temperature calculated by finite element analysis and formula (5) for a 1.5-m diameter CFST.

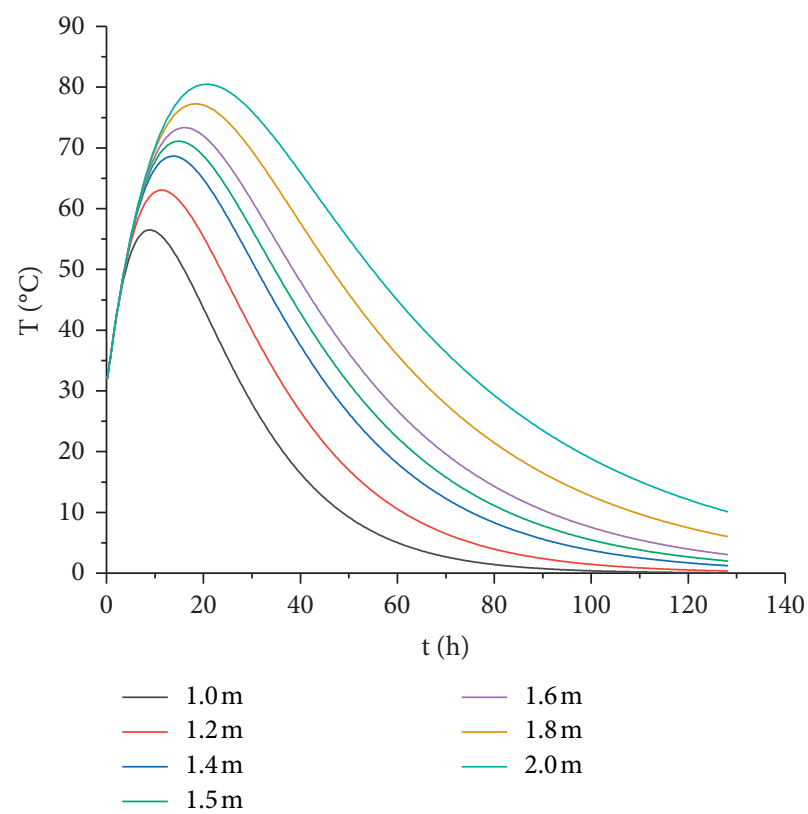

FIgURE 9: Center temperature curves of various finite element modeled CFST specimens.

$$
\alpha_{D}=-2.531 \times e^{-x / 1.155}+1.693
$$

4.3. Determination of Parameter $\beta_{r}$. The parameter, $\beta_{r}$ (the ratio of the temperature at the current location to that at the core), in formula (3) was determined by the following method. First, the 1.5-m diameter CFST member was simulated via finite element analysis, and the temperature curves of the nonshrinkage concrete were obtained at seven locations $(0, \mathrm{R} / 6, \mathrm{R} / 3, \mathrm{R} / 2,2 \mathrm{R} / 3,5 \mathrm{R} / 6 \mathrm{R}$, and $R$, where $R$ is the radius of the tube), as shown in Figure 11 . 


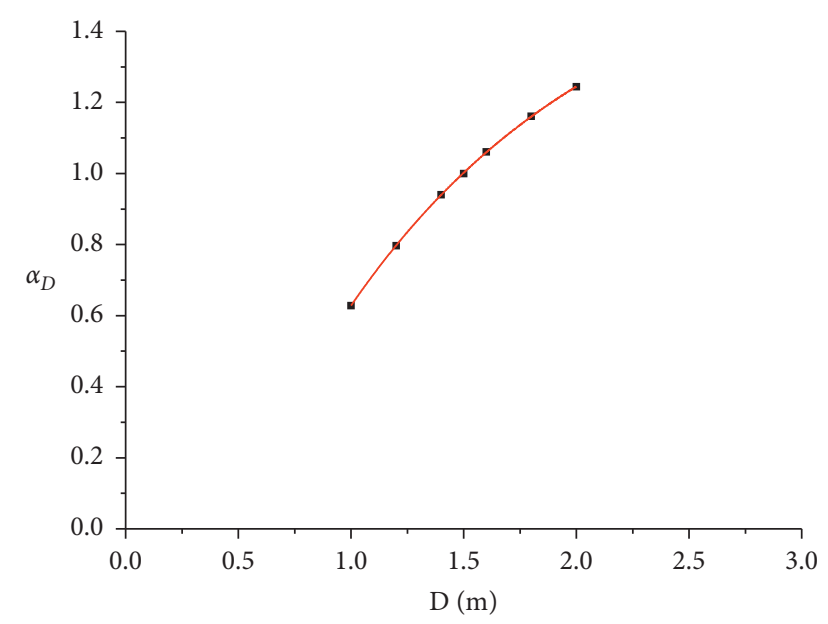

- Maximum temperature difference

— Fitted curve

Figure 10: Fitted curve of parameter $\alpha_{D}$ for different CFST diameters.

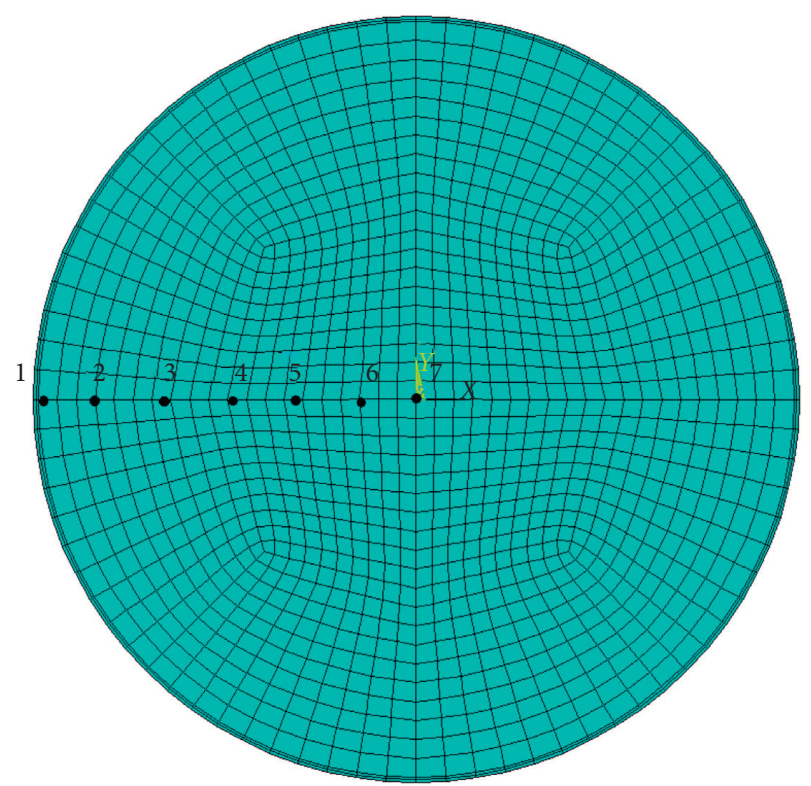

FIgURE 11: Measuring-point locations of the finite element model.

The resulting temperature curves are shown in Figure 12. Then, the ratios of the present locations to the radius of the CFST were taken as abscissa coordinates, and the ratios of the temperatures at each location to the center temperature were taken as ordinate coordinates, resulting in the seven points shown in Figure 13. The Origin software was then used to obtain the fitted curve through these points. Based on the center temperature of a $1.5-\mathrm{m}$ diameter CFST, the distance from the center of the CFST was set as the independent variable and $\beta_{r}$ was set as the dependent variable, resulting in the following fitting formula:

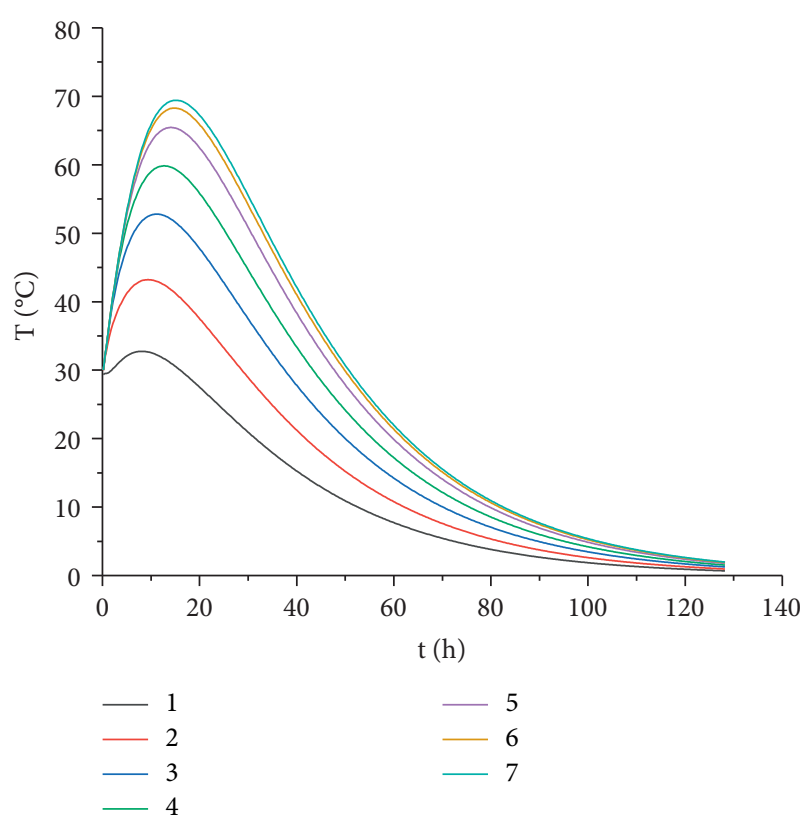

FIgURE 12: Temperature curves of concrete at different locations.

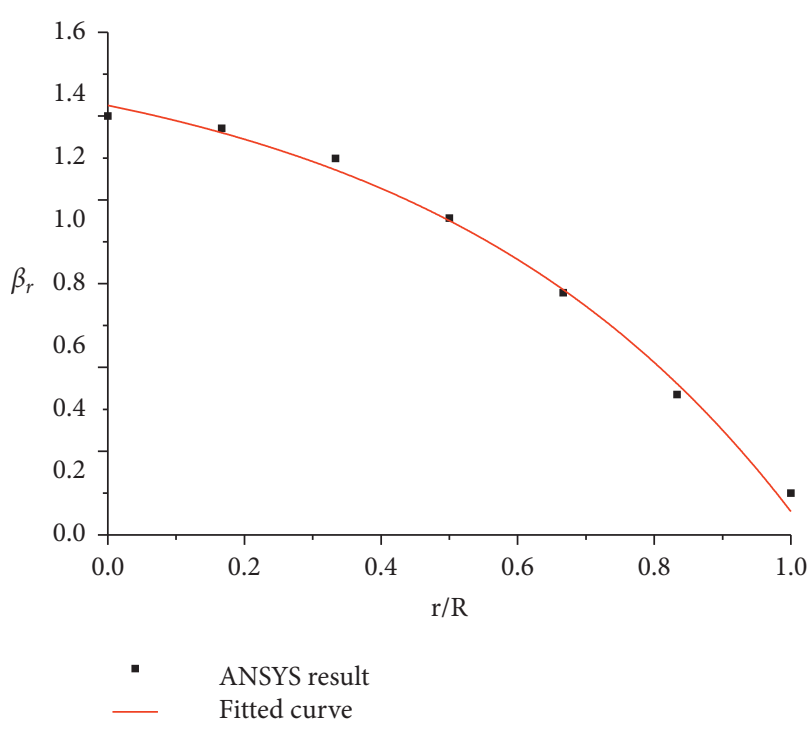

FIgURE 13: Fitted curve of parameter $\beta_{r}$. Note. A comparison of formulas (4) and (5) indicates that the expressions for the CFST diameter parameter, $\alpha_{D}$, and the CFST location parameter, $\beta_{r}$, are given in similar forms.

$$
\beta_{r}=-0.205 \times e^{x / 0.580}+1.233 .
$$

4.4. Discussion of the Application of the Proposed Formulas. The temperature curves of the 1.4- and 1.6-m diameter CFST members were calculated using formulas (3)-(5). The calculated curves, shown in Figures 14 and 15, can be observed to be consistent with the experimental results.

Based on the results of finite element calculation, the formula proposed in this paper only prolonged the 


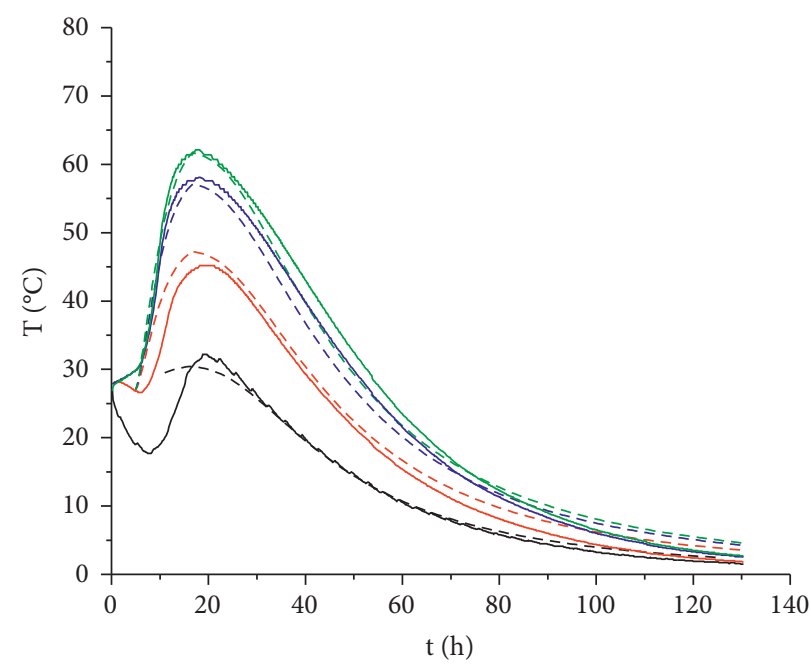

$\begin{array}{ll}\text { Experimental results } & \text { Formula results } \\ -1 & ---1 \\ -2 & ---2 \\ -3 & ---3 \\ -4 & ---4\end{array}$

Figure 14: Comparison of experimental and formula-calculated results for the 1.4-m diameter CFST member.

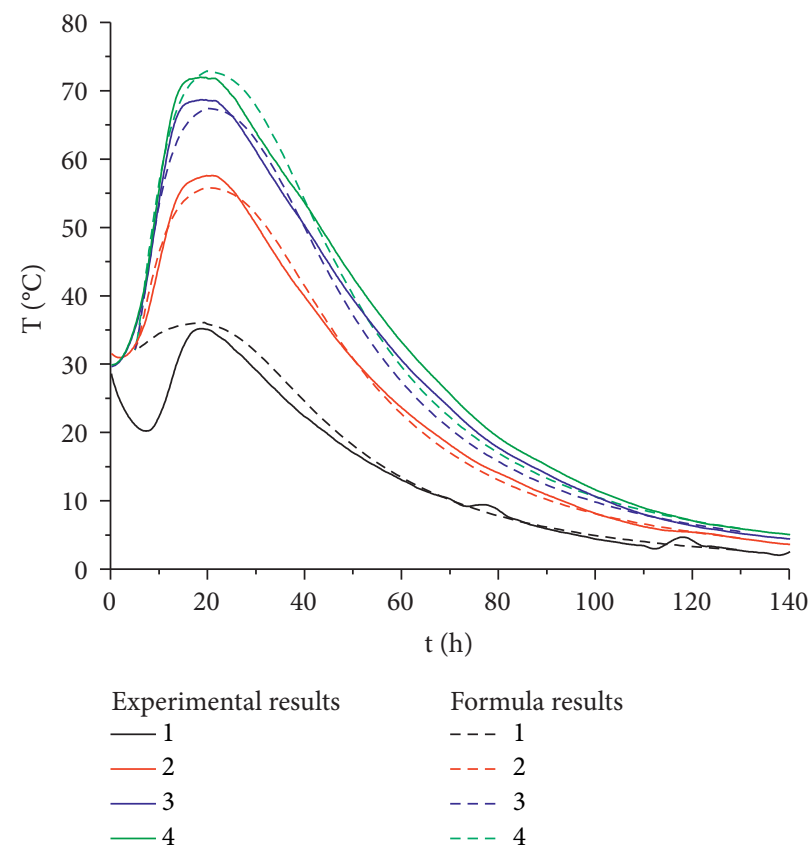

FIGURE 15: Comparison of experimental and formula-calculated results for the 1.6-m diameter CFST member.

retarding time of concrete, and the temperature change of edge concrete (No.1 measuring point) at the retarding section was not considered. Therefore, the formula results at No.1 measuring point were different from the experimental results at the retarding stage of concrete.

Furthermore, formulas (3)-(5) were applied using the data from three published studies $[18,19]$ to assess their consistency with the experimental results reported therein. The calculated curves, shown in Figures 16 and 17 , can be observed to be consistent with the experimental results in the literature $[18,19]$.

The improved formulas proposed in this study are therefore able to adequately predict the hydration heat in large-diameter CFST at low temperatures. 


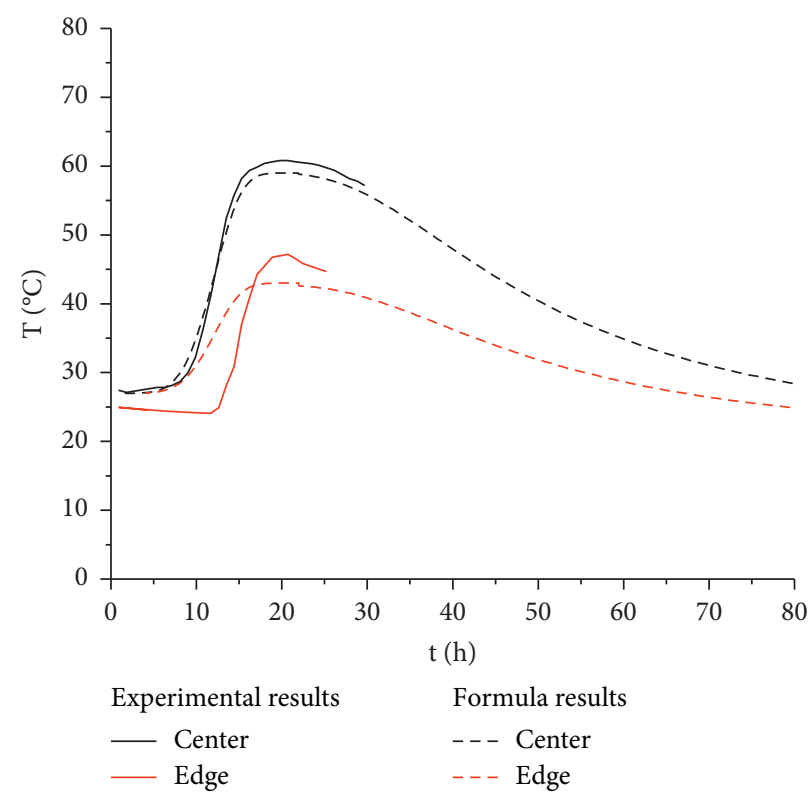

FIGURE 16: Comparison of formula-calculated results with the experimental results from Sun et al. [18].

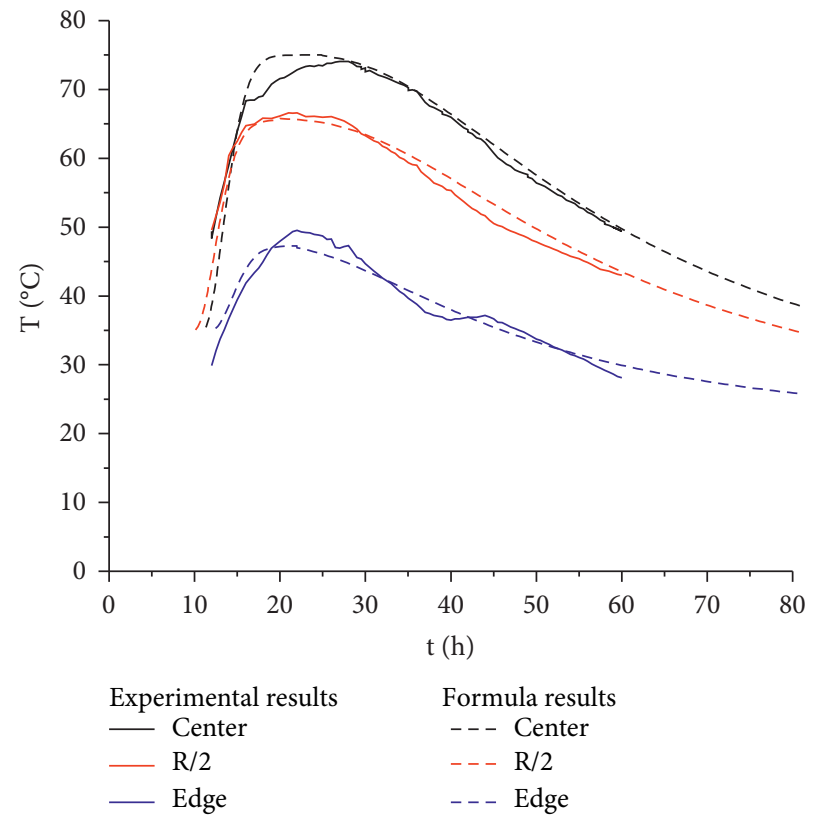

Figure 17: Comparison of formula-calculated results with the experimental results from Gao [19].

\section{Conclusion}

A series of CFST specimens were subjected to curing in a $0^{\circ} \mathrm{C}$ temperature-controlled room to observe the relationship between hydration heat and curing time according to the diameter of and location within the CFST specimens. The hydration-heat characteristics of CFST were observed to be similar to mass concrete, suggesting that there was a greater temperature difference caused by CFST hydration heat when cured at low temperatures. Owing to the low curing temperature and large temperature difference caused by hydration heat, the cooling rate of concrete was large.

A finite element model of hydration heat was then established, and its behavior was compared with the experimental results. The observed differences were then used to derive an improved formula for predicting the change in hydration heat according to CSFT parameters. The improved formulas proposed in this study were demonstrated to effectively predict the law of hydration heat in largediameter nonshrinkage CFST arch ribs at low temperatures of about $0^{\circ} \mathrm{C}$. 
Although limited to a single type of concrete in a small variety of CFST specimens cured at $0^{\circ} \mathrm{C}$ in this study, the research method applied can be extended to predict the hydration heat at many different locations in many differentdiameter CFSTs cured at different temperatures with various concrete-mix proportions.

\section{Data Availability}

The data used to support the findings of this study are available from the corresponding author upon request.

\section{Disclosure}

The funders had no role in the design of the study, in the collection, analyses, or interpretation of data, in the writing of the manuscript, or in the decision to publish the results.

\section{Conflicts of Interest}

The authors declare no conflicts of interest.

\section{Acknowledgments}

The authors would like to thank China Railway Guangzhou Engineering Group Co., Ltd. for materials used for experiments and Editage (www.editage.cn) for English-language editing. This research was funded by the National Natural Science Foundation of China (Grant nos. 51738004, 51868006, and 51878186), the Major Science and Technology Foundation of Guangxi (Grant no. AA18118029), and Project of Science and Technology Research and Development Plan of China Railway Corporation (2017G006-B).

\section{References}

[1] J. Zheng, "Development and prospect of long span arch bridges," China Highway, vol. 22, no. 24, pp. 41-42, 2017.

[2] J. Zheng and J. Wang, "Concrete-filled steel tube arch bridges in China," Engineering, vol. 4, no. 1, pp. 143-155, 2018.

[3] J. Zheng, J. Wang, Z. Feng et al., "Vacuum-assisted process test for concrete filled steel tube arch section," China Journal of Highway and Transport, vol. 27, no. 6, pp. 44-50, 2014.

[4] J. Zhou, X. Chen, and J. Zhang, "Early-age temperature and strain in basement concrete walls: field monitoring and numerical modeling," Journal of Performance of Constructed Facilities, vol. 26, no. 6, pp. 754-765, 2012.

[5] M. Briffaut, F. Benboudjema, F. Benboudjema, C. Laborderie, and J.-M. Torrenti, Creep consideration effect on meso-scale modeling of concrete hydration process and consequences on the mechanical behavior," Journal of Engineering Mechanics, vol. 139, no. 12, pp. 1808-1817, 2013.

[6] B. E. Byard, A. K. Schindler, and R. W. Barnes, "Early-age cracking tendency and ultimate degree of hydration of internally cured concrete," Journal of Materials in Civil Engineering, vol. 24, no. 8, pp. 1025-1033, 2012.

[7] Y. Zhou, D. Meng, and Y. Wang, "Finite-element simulation of hydration and creep of early-age concrete materials," Journal of Materials in Civil Engineering, vol. 26, no. 11, Article ID 05014006, 2014.

[8] A. Sedaghat, N. Shanahan, and A. Zayed, "Predicting one-day, three-day, and seven-day heat of hydration of Portland cement," Journal of Materials in Civil Engineering, vol. 27, no. 9, Article ID 04014257, 2015.

[9] W. Li, X. Li, S. Chen et al., "Effects of nanoalumina and graphene oxide on early-age," Journal of Materials in Civil Engineering, vol. 29, no. 9, Article ID 04017087, 2017.

[10] K. Hu, Z. Sun, and H. Yang, "Effects of polycarboxylate superplasticizers with different functional units on early hydration behavior of cement paste," Journal of Materials in Civil Engineering, vol. 31, no. 5, Article ID 04019041, 2019.

[11] Y. Tan, H. Yu, W. Bi et al., "Hydration behavior of magnesium oxysulfate cement with fly ash via electrochemical impedance spectroscopy," Journal of Materials in Civil Engineering, vol. 31, no. 10, Article ID 04019237, 2019.

[12] M. G. Chorzepa, H. Hamid, S. A. Durham et al., Analysis of Cracking Caused by Hydration Heat in Bridge Seals Utilizing Innovative Massive Concrete Mixtures, Structures Congress 2018: Bridges, pp. 167-175, Transportation Structures, and Nonbuilding Structures, Fort Wirth, TX, USA, 2018.

[13] B. Chen and A. Xu, "Temperature field analysis of concrete filled steel tube arch rib section," Journal of Harbin University of Architecture, vol. 32, no. 3, pp. 86-91, 1999.

[14] B. Feng, Study on Calculation Model of Hydration Heat Shrinkage and Creep of Core Concrete in Concrete Filled Steel Tube, Fuzhou University Learn, Fuzhou, China, 2004.

[15] C. Lin, J. Zheng, and R. Qin, "Analysis of the influence of hydration heat on the forming process of concrete filled steel tube arch ribs," Journal of Guangxi University, vol. 32, no. 2, pp. 186-188, 2007.

[16] C. Lin, J. Zheng, and R. Qin, "Finite element analysis of temperature distribution of hydration heat in concrete filled steel tubular section," China-foreign Highway, vol. 27, no. 4, pp. 125-127, 2007.

[17] J. Xuan, "Temperature field and thermal stress analysis of hydration heat of arch rib of concrete filled steel tube arch bridge," Bridge Construction, vol. 3, pp. 29-32, 2010.

[18] G. Sun, S. Li, W. Lu et al., "Temperature field test and numerical simulation analysis of hydration heat process cross section of concrete filled steel tube arch ribs with composite cementitious materials," Journal of Shandong University (Engineering Edition), vol. 41, no. 3, pp. 106-111, 2011.

[19] W. Gao, "Test and numerical analysis of hydration heat of long-span concrete filled steel tube arch bridge," Railway Construction, vol. 8, pp. 35-38, 2016.

[20] T. Shi, N. Deng, X. Guo et al., "Experimental study on deformation behavior and compressive strength of concrete cast in steel tube arches under low-temperature conditions," Advances in Materials Science and Engineering, vol. 2020, Article ID 8016282, 10 pages, 2020.

[21] B. Zhu, Temperature Stress and Temperature Control of Mass Concrete, China Electric Power Press, Beijing, China, 2003.

[22] M. H. Lee, B. S. Khil, and H. D. Yun, "Influence of cement type on heat of hydration and temperature rise of the mass concrete," Indian Journal of Engineering and Materials Science, vol. 21, no. 5, pp. 536-542, 2014.

[23] K. M. Koo, G.-Y. Kim, J.-K. Yoo et al., "Properties of adiabatic temperature rise on concrete considering content and setting time," Indian Journal of Engineering and Materials Science, vol. 21, no. 5, pp. 527-535, 2014. 